consideration, to provide against these risks by some slight addition to the Bill. I am, Sir, yours faithfully,

Queen Anne-street, W., March 30th, 1909.

FREDERIC HEWITT.

\section{THE BROMIDE TREATMENT OF EPILEPSY.}

In the Editor of The LANCET.

SIR, - I have read with great interest the excellent address of Dr. James Taylor on Some Points in Treatment of Nervous Diseases published in THE LANCET of March 27th. It contains many practical suggestions on the treatment of some common diseases of the central nervous system which cannot fail to be of use to the general practitioner. I, however, do not quite agree with the author in the prominence which he gives to what is usually described as the bromide treatment of epilepsy, which is probably the commonest of all nervous diseases met with in practice. Dr. Taylor regards bromide as our "sheet anchor" in epilepsy, by which disease I presume he means idiopathic epilepsy. He quite properly points out that such treatment is not unattended with certain dangers-for example, "acne" and "cardiac depression." There is, however, a still greater danger-namely, the production of cerebral depression caused by the chemical action of the drug on the delicate cortical neurons. Such action has been aptly described by Professor Mott as resulting from ohemical restraint of the nerve cells. It has been asserted that the prolonged administration of bromides is liable to incite changes in the cortical nerve cells indicating some degree of chomatolysis and even complete dissolution. Clinical observers in many of our largest asylums have noted that the continuous bromide treatment of their epileptics, whilst certainly tending to reduce the number of fits, produces in many cases that gravest of all mental diseases, dementia. It is, therefore, not surprising that in some of these institutions bromides are never used in the treatment of epileptics. Recent research points to the etiological factor in epilepsy being dietetic in nature, especially as regards the calcium metabolism of the body. Consequently it is advisable to place these patients on a farinaceous rather than a carbohydrate diet. and clinical observation prores that decided benefit results therefrom. Further, the daily administration of magnesium sulphate ( $3 \mathrm{i}$. doses) is found to have a beneficial effect. It is known that intraspinal injection of a solution of this drug causes paresis of the limbs, and apart from its laxative action it may be possible that its prolonged use results in diminishing in some way the conductivity of the efferent tracts. other points to be remembered in the treatment are suitable occupation, exercise, and warm baths, which latter are of use when the fits are very frequent. I would therefore arrange the points in treatment in order of their importance thus: (1) Dietetic ; (2) occupation and exercise ; (3) warm baths; (4) magnesium sulphate ; and (5) bromides.

I am, Sir, yours faithfully,

W. J. MagUIRE, B.A., M.D. R.U.I., M.R.C.P. Irel.

Belfast, March 29th, 1909.

\section{THE EXTENSION OF THE USEFULNESS OF COTTAGE AND OTHER HOSPITALS:} A SUGGESTION.

To the Editor of THE LANCET.

SiR,-It frequently occurs in the experiences of most general practitioners - especially those in outlying country districts-that poor patients are attacked with sudden illness which necessitates prompt surgical interference. Their removal to the nearest hospital over rough and dangerous roads, probably in an unsuitable vehicle, often adds to their sufferings and minimises their chances of recovery. Many a precious moment, and $\mathrm{I}$ may say many a valuable life, has been lost by this procedure. But what alternative has the general practitioner to suggest? The slender purse of his patient forbids the summoning of a consulting surgeon and a trained nurse, or if he is able to procure an anæsthetist he possibly feels himself incompetent to perform single handed some rare major operation. I may enlist your sympathies when I say that I reside some 14 miles from the nearest medical man, and when one or two of my experiences have been related the remedy which I suggest will be more readily understood.

During the last 12 months my partner and I have been called upon to perform 11 major operations, and fortunately all but three were able to pay the usual fee. But what about the three? It was as much as their lives were worth to attempt to remove them to a hospital ; the rough approach to their moorland homes, the nature and acuteness of their illness, and the absence of an ambulance or suitable vehicle forbade it. One case-a case of ruptured ectopic gestationoccurred at a most outlandish farmhouse with an impossible approach. With operating bags we had to wade through huge snowdrifts over ground where it was quite impossible to take a horse, much less a trap. As the internal hæmorrhage in this case was severe every moment was of importance, and as the nearest hospital was some 28 miles away and the roads were impassable the only thing to do was to operate "at home," and this we did. The patient made a rapid recovery and was well and about in six weeks. On Feb. 13th I was called to see a poor man's wife and acute appendicitis was diagnosed, probably with perforation. The total earnings of her husband were $24 s$. weekly, and in every way she was a suitable case for hospital treatment. Her removal was out of the question, as the peritonitis was rapidly spreading and delay was dangerous; moreover, the distance from hospital was some 22 miles. Fortunately, I was able to obtain an anæsthetist who motored over and brought a trained nurse with him, and with the nurse as my assistant I performed appendectomy, removing a very offensive and gangrenous appendix. The patient is doing well up to the present, but her only chance lay in the operation being performed "on the spot" with as little delay as possible. But the expense is far too heavy for their little income-the taxicab, the anæsthetist, and a trained nurse for at least a fortnight.

To my mind, something ought be done by all public hospitals for those patients with limited means who are not as fortunate as their fellow-sufferers in towns who happen to reside within the "call" of the ambulance. Let me suggest that all public hospitals, especially those which draw their patients from large agricultural districts, should establish a fund to be called "The Out-patient Emergency Fund"; this fund to be expended in providing for an operation in cases of emergency unfit for removal and suitable for hospital treatment. Could not some hospitals arrange that their surgeons should be motored out to such cases as I have described, the expenses to be charged to the fund? The surgeon, if necessary, could take with him the hospital anæsthetist and a "theatre" nurse, or where the surgeon did not require an assistant the general practitioner would give the anæsthetic. The medical men in attendance on these cases ought to be privileged to "wire" to the nearest hospital for assistance, using a code word as may be agreed upon-for example, I should suggest some such message as this, viz. " - Hospital, York. OPEF. Appendectomy. Jones, Castlegate, Church Fenton. Dr. Roberts." The code word OPFF. would signify that it was a poor patient entitled to the benefits of the Out-patient Emergency Fund ; the second word would give the probable nature of the operation, and the following would give name and address of patient and medical man. The hospital authorities might even go so far as to provide a fortnight or three weeks' surgical dressings, according to the nature of the operation.

Of course, it would be necessary to safeguard against the abuse of such a scheme, and to do this effectually the surgeon should have the right to refuse to operate on his arrival if he thought the emergency not sufficiently great or his patient unsuitable for hospital treatment. Looking at it from the hospital's point of view, the expense would not be any greater than if the case was admitted to one of their beds. The cost of the motor hire would probably be equivalent to a patient's three weeks' board in hospital, taking an average. I find it possible to hire a taxicab for a distance of between 20 to 25 miles, to remain an hour or two before returning, at the cost of 2 guineas for the round trip. This would mean that, for example, a case of perforated gastric ulcer could be dealt with by an experienced hospital surgeon at a distance of 20 miles and two or three weeks' dressings supplied at a total cost of about 3 guineas to the emergency fund. Then all the patient would be called upon to provide would be the usual visiting fees of the general practitioner and occasionally (where the services of the district nurse could not be obtained) the 
charges of a trained nurse for a week or two. This would remove the onus of heavy expenditure which poor country people are often called upon to meet in such cases, and it would also greatly enhance the chances of the patient's recovery. Exception cannot be taken to operating in such surroundings as the country cottager can provide, as I believe that the pure country air, with its freedom from septic microorganisms, is far preferable to the germ-laden atmosphere of a "theatre" in a general hospital, however saturated it may be with antiseptic vapours. One can quite credit the result obtained in the "proverbial Cæsarean section" performed in a woodman's hut with the aid of a pocket-knife and "wax-end" for ligatures.

Finally, I appeal to hospitals generally, and to cottage hospitals in large agricultural districts in particular, to give some such scheme their earnest consideration. I feel sure that they would enlist the sympathies and support of their honorary surgical staff, and by so doing they would be conferring a blessing on the suffering poor in country districts and be offering a valuable privilege to the general practitioner. I am, Sir, yours faithfully,

G. Metcalfe Sharpe.

Angram, Middlesmoor, Leeds, March 19th, 1909.

\section{THE CLINICAL VALUE OF HæMOMANO- METER OBSERVATIONS.}

\section{To the Editor of THE LANCET.}

SiR,-In my letter in THe LaNCET of March 13th I dealt with the two sets of observations made by Dr. Leonard Hill and which he held absolutely disproved my contentions that the arterial wall was ever a factor in hæmomanometer observations. In the first set of observations I compared the obliterating pressure in the posterior tibial when the whole body was horizontal with the pressure when the limb was in the "L position, the leg up." If language has any definite meaning this meant that the limb was at right angles to the trunk, and yet in his letter in THe LANCET of March 27th he says "their legs were hoisted up to unequal extents." He further says : "The whole point of this experiment is that the measurements in arm and leg came out fairly well in comparison with the column of blood separating the two places of measurement." My contention is that it was simpler and fairer to compare the pressure when the limb was horizontal with what it became when vertical, and his own figures showed in the three subjects that the change to the vertical led to loss of pressure in one subject of $21 \mathrm{~mm}$. $\mathrm{Hg}$, in another of 48, and in a third of 62 . Dr. Hill has not met this criticism fairly, for if the limbs of the three subjects differed so much, as he now suggests, he got the height of the column of blood extraordinarily near each other. In fact, it was, apparently, the similarity of the figures he succeeded in getting that led him to contend that the manometer reading was blood pressure, and blood pressure only. Dr. Hill's explanation of the phenomenon is not complete. I have made corresponding observations on the forearm when horizontal and vertical, and find corresponding differences without any difference in the length of the arm as measured from the axilla. Dr. Hill need not therefore run away from his observations, but as proofs against my contention that the arterial wall when thickened affects the amount of pressure required to obliterate the artery they fall to the ground.

With regard to the second set of observations, I pointed out that Dr. Hill could only get the venous pressure as high as the arterial by his method of investigation, as he stopped any further engorgement on the distal side of the bag on the forearm when he reached the arterial obliteration pressure. This I still maintain to be a quite apparent fallacy in his method. With regard to his criticism of my method, firstly, the wristlet I used was not an " unenclosed bag," but enclosed in the same way as the armlet; secondly, I could repeat Dr. Hill's observations up to the point at which the artery was obliterated with the wristlet applied to the entire circumference of the arm ; thirdly, I have found that when the wristlet was applied to a radial artery winding to the back of the wrist I could obliterate it with a pressure of $30 \mathrm{~mm}$. Hg less than was required to obliterate the brachial by the armlet; and fourthly, when applied to a venous trunk the same must be true. I maintain that my method measures the venous engorgement pressure, while Dr. Hill's cannot do so. From Dr. Hill's criticism I might imagine I had made an important physiological discovery in finding that venous engorgement pressure can rise far above arterial pressure had I not found that Professor Starling in his eighth Mercers' Company lecture on the Fluids of the Body gives experiments on an animal in which at the beginning the artery gave a pressure of 110 and the vein 140 , then, when the arterial pressure was reduced to 50 , the venous pressure rose to 175-over three times the arterial pressure. Here, again, in his desire to find me wrong he has forgotten observations with which I presume be is more or less acquainted ; and commits himself to the view that my findings would "seriously upset the ordinary laws of physics," ignoring thereby the further fact that we are dealing with vital phenomena, not physical laws. The impossible to physiology, as represented by Dr. Hill, again becomes demonstrable fact! And Dr. Hill's second set of observations in no way weaken my contention with regard to the arterial wall.

I shall only deal with one other point in his letter, for I decline to be drawn into an extension of the area of controversy, and that point is that Dr. Hill says that I "maintain the view that the heart has no reserve power to with. stand a pressure of more than about $20-30 \mathrm{~mm}$. above the normal." I nowhere have made any such statement. The reference is apparently taken secondhand from Dr. William. son, who referred not quite accurately to an argument in my book based on Dr. Hill's own statement in Schäfer's "Physiology," that after violent exercise the blood pressure rose 20-30 $\mathrm{mm}$. with a "normal average heart." Dr. Hill further adds that "physiologists know that the blood pressure can easily be doubled in an animal by the injection of suprarenal extract." Had he referred to my book, which he says he has read, he would have found that I had not overlooked that fact, but that I had added that to get this pressure the vagus had to be cut. I have not troubled to refresh my memory as to whether that statement also was or was not taken from Dr. Hill's own writings; but I presume it is well known to experimental physiologists, and, if so, why did Dr. Hill suppress the fact? Other statements equally inaccurate occur in the letter, but $I$ have neither the time nor the inclination to deal with them, even if you, Sir, were willing to allow me space in the pages of THE LANCET for the purpose. If Dr. Hill really seeks enlightenment on clinical and pathological phenomena I should be charmed to help him, but as a preliminary a more accurate knowledge of my writings, which he professes to have read, would be desirable.

Edinburgh, March 27th, 1909. I am, Sir, yours faithfully,

\section{To the Editor of THE LANCET.}

SIR,-Dr. Leonard Hill in THE LANCET of to-day asks whether the arm and leg readings which I obtained in pathological cases were "measured simultaneously, with one armlet on the arm and the other on the leg connected with one manometer, and the observer feeling radial and posterior tibial at the same time." In the 21 high-pressure cases and ten cases of normal or low blood pressure without evidence of arterial disease, of which the results will shortly be published, the leg and arm readings were made successively.

I quite admit that to draw conclusions from one case in which arm and leg readings are made it is essential, as Dr. Hill says, that the readings should be made simultaneously. I believe, however, that in taking the average difference from a large number of cases as I have done any error due to the arm and leg readings not being simultaneous will be eliminated. That this is so is I think sufficiently shown by the fact that in my series of cases of normal or low blood pressure without evidence of arterial disease the average difference between the systolic arm and leg readings is less than two millimetres, and that both this series and that of cases of high blood pressure yielded on the average an identical diastolic arm and leg reading.

Since completing my paper, however, I have made simultaneous arm and leg readings on five high-pressure cases, and in four of these have found the leg readings to be distinctly higher than those on the arm; moreover, in two of the cases the difference was a very marked one. I have in these adopted both the above method recommended by $\mathrm{Dr}$. Hill and another plan. In this the armlet on the leg is con. nected with one manometer, that on the arm with another. 